\title{
Housing and inequalities in health: a study of socioeconomic dimensions of housing and self reported health from a survey of Vancouver residents
}

\section{J R Dunn}

Correspondence to:

Professor J R Dunn,

Department of Community Health Sciences, The

University of Calgary,

3330 Hospital Drive NW,

Calgary, Alberta, Canada

T2N 4N 1 ;

jimdunn@ucalgary.ca

Accepted for publication 4 February 2002
Study objective: To investigate the relation between housing, socioeconomic status, and self reported general and mental health. This study is an empirical investigation of social and economic dimensions of housing, specifically, demand, control, and material (affordability, dwelling type) and meaningful (pride in dwelling, home as a refuge) dimensions of everyday life as they occur in the domestic environment.

Design: A cross sectional telephone survey was administered to a random sample of households. Survey items included measures of demand, control, and meaningfulness of the domestic environment, as well as standard measures of socioeconomic status and social support. Main outcome measures were self reported health (excellent, very good, good, fair, poor) and self reported frequency of feeling "downhearted and blue" in the two weeks before interview (from the Rand Mental Health Index).

Setting: Households ( $\mathrm{n=650}$ ) from 12 neighbourhood areas in the city of Vancouver, Canada.

Participants: One randomly selected adult from each of 650 households completed the interview and constitute the sample for this study.

Main results: In bivariate analyses, measures of housing demand, control and meaningfulness exhibited strong and significantly graded relations with self reported health and somewhat less strong relations with mental health. In logistic regression analyses housing demand and control variables made significant contributions to health both general and mental health. Respondents were more likely to report fair/poor health if they: reported that they couldn't stand to be at home sometimes $(O R=2.29$, $p<0.05)$; rated their domestic housework as somewhat or quite a strain $(O R=5.71, p<0.001)$; were somewhat or very dissatisfied with their social activities (OR=3.41, $p<0.001)$; and reported that they were constantly under stress a good bit of the time or more $(O R=3.56, p<0.05)$. In terms of mental health, respondents were more likely to report poorer mental health if they: lived longer in their neighbourhood $(O R=1.05, p<0.05)$; reported their housework duties to be somewhat or quite a strain $(O R=5.55, p<0.001)$; reported that they did not have somebody that could help them if they needed it $(O R=9.28, p<0.001)$; and reported that they were constantly under stress a good bit of the time or more in the two weeks before the interview $(O R=5.26, p<0.001)$. One of the main hypotheses investigated -that meaningful dimensions of housing are associated with health status - found support in bivariate analyses without controls, but did not contribute to multivariable models.

Conclusions: The influence of housing demand and control variables superseded a well known correlate of health status, educational attainment, attesting to their importance. The findings of this paper lend support to the hypothesis that features of the domestic environment, especially as they pertain to the exercise of control and the experience of demand, are significant predictors of self reported general and mental health status. Housing is a concrete manifestation of socioeconomic status, which has an important part to play in the development of explanations of the social production of health inequalities.
A one time, there was a strong convergence between analyses of socioeconomic inequalities in housing and socioeconomic inequalities in health in industrialised countries. The link between housing conditions and the transmission of infectious disease was a crucial component of the public health reforms of the 19th century. ${ }^{2}$ But the decline of infectious disease during the late 19th and early 20th centuries, emblematic of the epidemiological transition, has largely severed one dimension of the logical link between housing conditions and health-that of infectious disease transmission.

In the contemporary era, by contrast, it is well established that in the industrialised countries of the world there exists a monotonic gradient in the relation between social status and health status, no matter how each is measured. Greater income, education, and occupational class are all positively related to better health, whether measured by positive health status or the propensity to experience injury, morbidity, or mortality by nearly any cause. The social gradient in health spans the entire social spectrum and cannot be attributed solely to the effects of reverse causation, access to medical care, genetics, nor adverse health behaviours. ${ }^{3}$ The benefits of relative affluence and prestige are believed to translate into biological outcomes through the cumulative effects of attenuated physiological stress responses across the life course. ${ }^{56}$ Sustained, chronic stress is known to stimulate immunosuppression and promote a maladaptive stimulation of the neuroendocrine system, leading to a wide range of life threatening conditions, including cardiovascular and coronary heart disease. ${ }^{5-7}$

Despite the widespread agreement about the existence of the social gradient in health, and the plausibility of biological mechanisms underlying it, there is little agreement about the relevant factors for the social production of health inequalities. There are two logical arguments, however, that can give rise to an emergent framework of understanding.

Firstly, one thing that is clear from the available evidence is that the social gradient in health is not only about income, even among the most affluent of industrialised societies. The relation between income and health status holds for educational 
attainment and occupational grade, which are not entirely concordant with income. Income is important at the extreme low end of the spectrum, of course, as it buys necessities of daily living-adequate nutrition, shelter, clothing, etc, but beyond subsistence levels, what does income buy? One thing it is associated with is better psychosocial working conditions, which have been shown to strongly influence health. A great deal of evidence suggests that the most important dimensions of the work environment are: psychological job demand, task control (or decision latitude), and social support. The more demanding the job, the less the control and the less the social support, the greater the health risk for a wide variety of conditions. ${ }^{8}$ If these are the three most important attributes of workplace conditions for health, it follows that similar factors must be important during the other 16+ hours of the day, and that the home would be a logical nexus for such influences to occur.

The second logic informing a new framework for understanding health inequalities follows from the work of Richard Wilkinson. ${ }^{3}{ }^{10} \mathrm{He}$ argues for a "psychosocial interpretation" of the social gradient in health, claiming that:

\section{"psychosocial factors related to deprivation and disadvantage are involved. That is to say, it is less a mat- ter of the immediate physical effects of inferior material conditions than of the social meanings attached to those conditions and how people feel about their material cir- cumstances and about themselves. ${ }^{10}$ (emphasis added)}

This study uses social survey methods to investigate the relation between housing, socioeconomic status, and self reported general and mental health. Housing is understood to have both significant material dimensions (housing costs, wealth generation and storage, controlled physical environment, protection from elements, etc) and meaningful dimensions (housing as a reflection of self identity and pride, a place of refuge, a site for the exercise of control, a source of social status, etc) for health. ${ }^{11}{ }^{12}$ This study is an empirical investigation of the support for a convergence of logical arguments concerning the importance of demand, control, and material and meaningful dimensions of everyday life to the social production of social gradients in health status-in this case, as they occur in the domestic environment. Conceptually, the following analysis investigates the empirical basis for a contemporary convergence of housing, socioeconomic status, and health inequalities.

\section{METHODS}

\section{Participants}

All adult residents of households in the city of Vancouver, Canada were eligible for inclusion in this study. The survey was administered by telephone to a random sample of households in 12 neighbourhood areas $(n=650$ total). One adult individual was randomly chosen within each household to participate in the survey. Neighbourhood areas were defined on the basis of a recent mortality atlas of Vancouver that roughly conform to neighbourhoods used by the City of Vancouver's Planning Department for neighbourhood area planning. ${ }^{13}$ Survey administration was conducted in a way that attempted to achieve an equal number of completed interviews across the 12 neighbourhood areas.

The survey was administered by a Vancouver based survey research firm between 3 May 1999 and 16 June 1999. The sampling frame was purchased from Dominion Directories Information Services, a division of the Stentor Group of Companies, the company that compiles telephone listings for most Canadian cities. Their listings are updated monthly, and contain all households and businesses with telephones. Their listings do not, however, include the numbers of households who have asked that their number be unlisted. As households with unlisted numbers are more likely to be affluent, inferences about the upper portions of the social spectrum must be drawn from the current dataset cautiously. A random sample of 5000 telephone numbers with Vancouver based postal codes was purchased from Dominion for use as the sampling frame. A Computer Assisted Telephone Interviewing (CATI) system then drew telephone numbers randomly from the sample frame until 650 completed interviews had been achieved. In total, 4137 numbers were attempted: 3962 were deemed eligible (that is, in service, not a fax, not a business), 2965 potential respondents were contacted and asked to participate, and 2054 cooperative contacts were reached. Of these, 1404 were disqualified, usually because the quota for their neighbourhood had been reached. The remaining 650 completed the interview and constitute the sample for this research. Overall, the administration of this questionnaire achieved good response rates. The refusal rate was $30.7 \%$, the crude response rate was $51.8 \%$ (cooperative contacts $\div$ total asked to participate), and the adjusted response rate was $69.3 \%$ (cooperative contacts $\div$ total number eligible phone numbers).

\section{Housing and socioeconomic status measures}

The questionnaire administered to respondents included a number of items intended to tap constructs related to respondents' investment of meaning in the home ${ }^{1112}$ and neighbourhood ${ }^{14}$ and their experience of demand and control in the domestic environment. Respondents were asked to rate on a Likert scale the extent to which they: (a) felt like they belonged in their neighbourhood, (b) were proud to live in their neighbourhood, (c) were proud to show their home to visitors, (d) felt like they couldn't stand to be at home sometimes (home as place of refuge), (e) felt like their home was well located to meet their everyday needs, (f) felt like their home reflected their identity, (g) were worried about being forced to move, and (h) felt like it was a strain to meet their monthly housing costs. In addition, respondents were asked to estimate how many hours per week they spent doing household chores and how much of a strain they found their domestic workload.

In several items respondents were asked to report on both their general (do you have someone you can confide in?, is there someone who can help them if you need it?, in general, how satisfied are you with your social activities?) and neighbourhood based social ties (how friendly are your neighbours?, how often to you talk with your neighbours?). The survey also collected respondents' basic sociodemographic characteristics (age, sex, marital status, employment status, education, income, etc).

\section{Outcome measures}

Two self reported health status measures were used: general self reported health (fair/poor as opposed to good/very good/excellent) and a single item from the Rand Mental Health Inventory (MHI) ${ }^{15}$ - "how much of the time in the past two weeks have you felt downhearted and blue?" (response categories were: all of the time, most of the time, a good bit of the time, some of the time, a little of the time, none of the time). The former measure is used widely ${ }^{16}$ and has been shown to be highly correlated with other "harder", physical measures of health (mortality, diagnosed morbidity, symptom reporting $)^{17}{ }^{18}$ and also functional status. ${ }^{19}$ In general, the MHI is a robust screening instrument that can predict, with acceptable accuracy, the likelihood that a person suffers from clinically diagnosable depression or anxiety. It measures mental health in terms of psychological distress and wellbeing, focusing on affective states, and was developed for use in population surveys. ${ }^{20}$ The single MHI item "downhearted and blue" was selected for inclusion in this survey to minimise respondent burden and provide an efficient means to assess mental health and wellbeing. There is evidence to suggest that this item has the capacity to adequately and efficiently assess mental health and wellbeing, performing even better than the General Health Questionnaire (GHQ), using diagnoses from the Diagnostic Interview Schedule (DIS) as the standard for comparison. ${ }^{21}{ }^{22}$ 
Table 1 Descriptive statistics. Housing and quality of life in Vancouver

\begin{tabular}{|c|c|c|c|}
\hline \multirow{3}{*}{$\begin{array}{l}\text { Gender } \\
\% \text { female }\end{array}$} & \multirow{3}{*}{54.3} & \multicolumn{2}{|l|}{ Household characteristics } \\
\hline & & Mean number of people per household & 2.53 \\
\hline & & Median number of people per household & 2.0 \\
\hline \multicolumn{4}{|l|}{ Age distribution of sample respondents } \\
\hline $18-34$ & 39.3 & Mean crowding index (bedrooms per person) & 1.04 \\
\hline $35-54$ & 42.0 & & \\
\hline $55-64$ & 7.2 & Mean length of residence in current dwelling (years) & 7.18 \\
\hline 65 or older & 10.5 & Median length of residence in current dwelling (years) & 3.04 \\
\hline Marital status & & Mean length of residence in current neighbourhood (years) & 10.1 \\
\hline$\%$ married or common law & 50.3 & Median length of residence in current neighbourhood (years) & 5.0 \\
\hline \multirow[t]{2}{*}{$\%$ single } & 34.2 & & \\
\hline & & $\%$ of respondents spending $>30 \%$ of income on housing $\dagger$ & 41.9 \\
\hline Education & & $\begin{array}{l}\% \text { of respondents who find it somewhat or extremely difficult to meet monthly } \\
\text { housing costs }\end{array}$ & 42.0 \\
\hline$\%$ with less than high school education & 6.0 & & \\
\hline$\%$ completed high school & 18.5 & Housing demand / control / meaning & \\
\hline \multirow[t]{2}{*}{$\%$ completed university } & 35.2 & $\%$ agree or strongly agree & \\
\hline & & I feel like I belong in neighbourhood & 85.2 \\
\hline Income* & & I feel proud to live in my neighbourhood & 84.5 \\
\hline$\%$ with income less than $\$ 25000$ & 19.1 & I am proud to show my home to visitors & 81.1 \\
\hline$\%$ with income between $\$ 25000$ and $\$ 59999$ & 30.6 & I can't stand to be at home sometimes & 22.2 \\
\hline \multirow[t]{2}{*}{$\%$ with income greater than $\$ 60000$} & 26.8 & My home provides a good place to live my life & 90.3 \\
\hline & & I often worry about being forced to move & 12.6 \\
\hline Dwelling characteristics & & My home is a good reflection of who I am & 80.6 \\
\hline$\%$ living in single house & 38.5 & & \\
\hline$\%$ living in semi-detached house & 10.2 & Respondents' health status & \\
\hline$\%$ living in self contained apartment in a house & 8.8 & $\%$ reporting fair / poor health & 10.5 \\
\hline$\%$ living in low rise apartment & 26.5 & $\begin{array}{l}\% \text { reporting feeling downhearted and blue 'a good bit of the time' or more in } \\
\text { past } 2 \text { weeks }\end{array}$ & 11.2 \\
\hline$\%$ living in high rise apartment & 15.8 & $\%$ reporting feeling constantly under stress 'fairly often' or more in past 2 weeks & 26.3 \\
\hline Housing tenure & & $\%$ of households with resident with a physical disability & 7.8 \\
\hline$\%$ who own their home & 45.4 & & \\
\hline
\end{tabular}

\section{Statistical analysis}

Statistical analysis was performed using SPSS 10.0 software. Descriptive statistics showing the frequencies of selected variables are presented in the first instance. This is followed by bivariate analyses using non-parametric tests of significance for measures of interest (with emphasis on meaning, demand, and control). The final component of the analysis uses logistic regression analysis to investigate the simultaneous influence of housing related and other socioeconomic variables on the health outcomes. To calculate the models, self rated health status was dichotomised into two categories, "fair/poor" on the one hand, and "excellent/very good/good" on the other. The mental health indicator, "downhearted and blue" was dichotomised as "all the time/most of the time/a good bit of the time" on the one hand, and "some of the time/a little of the time/none of the time" on the other, where more often implies a greater likelihood of poorer mental health.

In the logistic regression analysis, explanatory variables measured at the ordinal level were dichotomised by aggregating existing categories. Each item was considered individually, and in instances where a variable containing five categories had to be reduced to two, a conservative approach, based on the expected direction of effect, was taken. For example, pride in one's dwelling was hypothesised to be positively related to the health outcomes, and so in dichotomising that variable, respondents who strongly agreed or agreed were aggregated in one category, and respondents who were neutral, disagreed, or strongly disagreed were placed in the other.

In calculating the logistic regressions for each outcome, a model was constructed sequentially whereby variables were entered in conceptually coherent blocks in an additive fashion, keeping only those variables that made a contribution to the model before adding the next block. The only exception to this was in the case of the first block of variables (age, gender, educational attainment of respondent, and housing tenure), which were forced into the model because of their a priori importance. Models were run using a backward stepwise elimination procedure, and variables were judged to contribute to the model if the significance level for the Wald inclusion statistic was 0.10 or lower.

\section{RESULTS}

\section{Descriptive results}

Table 1 shows descriptive results from completed surveys. Mean length of residence in dwelling was 7.18 years while mean length of residence in current neighbourhood was 10.1 years. These differ from median length of residence in dwelling and neighbourhood, 3.04 and 5.0 years, suggesting a modest but not insubstantial degree of residential transience. Roughly $42 \%$ of respondents reported that they spend more than $30 \%$ of their monthly income on housing costs and a similar proportion reported that they found it somewhat or extremely difficult to meet their monthly housing costs. For each of the survey questions designed to assess housing demand, control and meaning, between $10 \%$ and $20 \%$ assessed their housing situation negatively. In terms of health status measures, $10.5 \%$ of respondents rated their health as fair or poor, while $11.2 \%$ reported feeling downhearted and blue "a good bit of the time" or more in the past two weeks. Finally, 26.3\% reported feeling "constantly under stress" "fairly often" or more in the past two weeks, while $7.8 \%$ reported that they had a disability, although no further information about the nature of individuals' disability was sought.

\section{Bivariate analyses}

The results of selected non-parametric tests for significant intergroup differences are displayed in histograms in Figures $1 \mathrm{~A}$ to $6 \mathrm{~B}$. The objective of displaying the results of these analyses in this way is to look for gradients in demand, control, and meaningful dimensions of housing on the one hand, and the two health outcomes, on the other. The numbers on the y axes of these histograms have no intrinsic meaning, they are simply the 


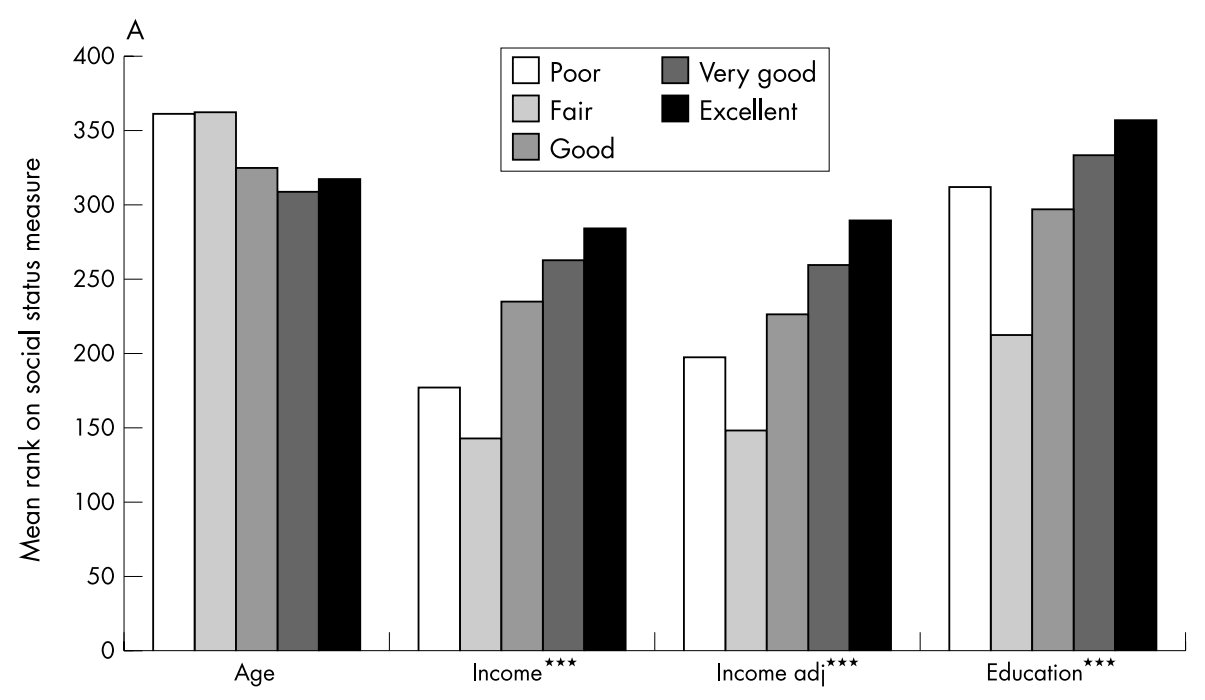

Figure 1 (A) Social status and health status. (B) Social status and mental health. ${ }^{*} p<0.05,{ }^{* *} p<0.01$, ${ }^{* * *} p<0.001$.

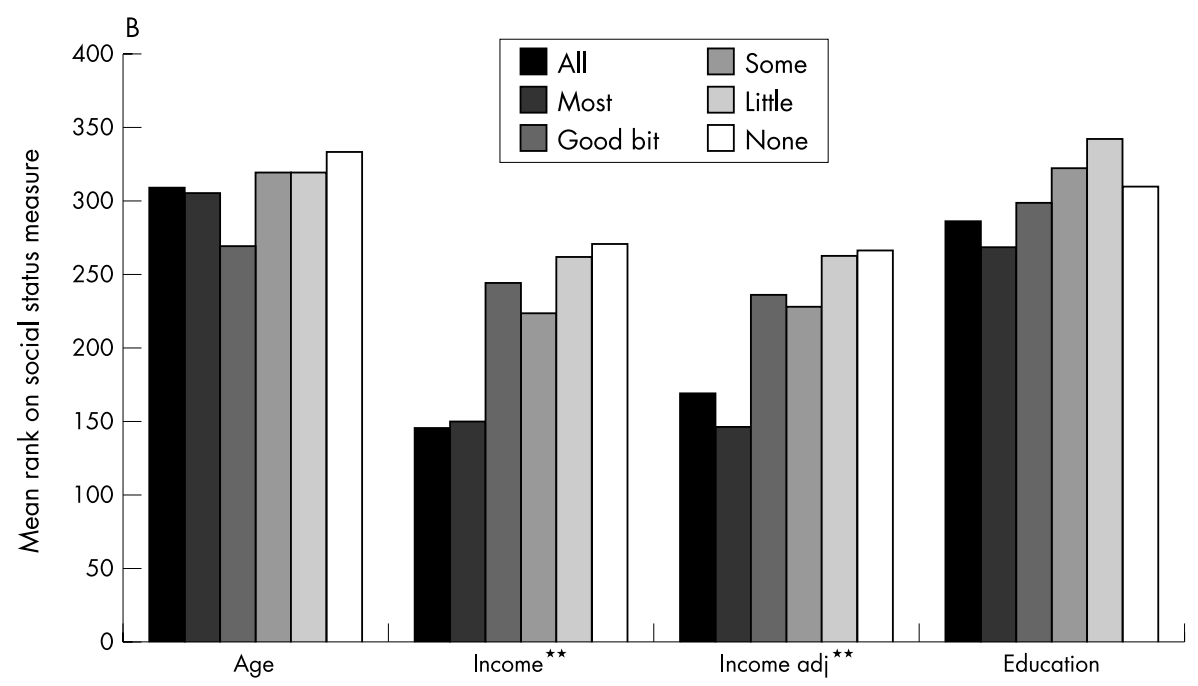

mean of the ranking of all respondents (in a given health category) on the test variable. On the whole, there is evidence of a graded relation between a number of dimensions of housing and self rated health, with somewhat less defined gradients in the mental health measure. Beginning with figure $1 \mathrm{~A}$, there is evidence of a statistically significant income gradient and a statistically significant educational gradient in self rated health status, and a non-significant relation between age and health status. The income gradient in health remains significant after adjusting for household size by dividing household income by the square root of the number of people in the household. The unusually high mean rank on income and educational attainment for respondents reporting poor health is the only deviation from the gradient pattern, and further analyses (not reported) suggest that this anomaly could be attributable to a small number of respondents who simultaneously reported poor health, a disability, and high income and educational attainment. Figure 1B shows similar results for the mental health measure, but with gradients that are somewhat attenuated. Nevertheless, statistically significant, graded relations can be observed for income, income adjusted for household size, and educational attainment.

Figure $2 \mathrm{~A}$ shows that household attributes have little or no relation with self rated health, and where a significant relation exists, it is not a gradient. The results are similar for the mental health status measure (fig $2 \mathrm{~B}$ ). There was little evidence of a social gradient in mental health for number of persons in household, crowding (persons per bedroom), length of residence in dwelling or length of residence in neighbourhood.

A different picture emerges when considering material dimensions of housing, as measured by both objective and subjective measures of the burden of housing costs (relative to income). Figure 3A shows a weak and inconsistent, but statistically significant gradient between crude housing costs and self rated health. For mental health (fig 3B), differences in reporting "downhearted and blue" are statistically significant, but there is not a consistent, monotonic gradient. When measured relative to income, housing costs strongly and significantly differentiate between respondents with poor or fair self rated health and the remainder of the sample (fig 3A). For mental health, modest evidence of a statistically significant housing affordability gradient in mental health status is shown in figure 3B. Capital gains on current residence (in 1996 dollars) were calculated for the subset of respondents who were owner-occupiers and who provided complete information on purchase price, length of ownership, current estimated market value, and outstanding mortgage sums $(n=167)$. No statistically significant differences were found for either self reported health or mental health. For most households, housing represents their single largest monthly expenditure and their single largest asset. Capital gains, it follows, can be interpreted as markers of household wealth/ 


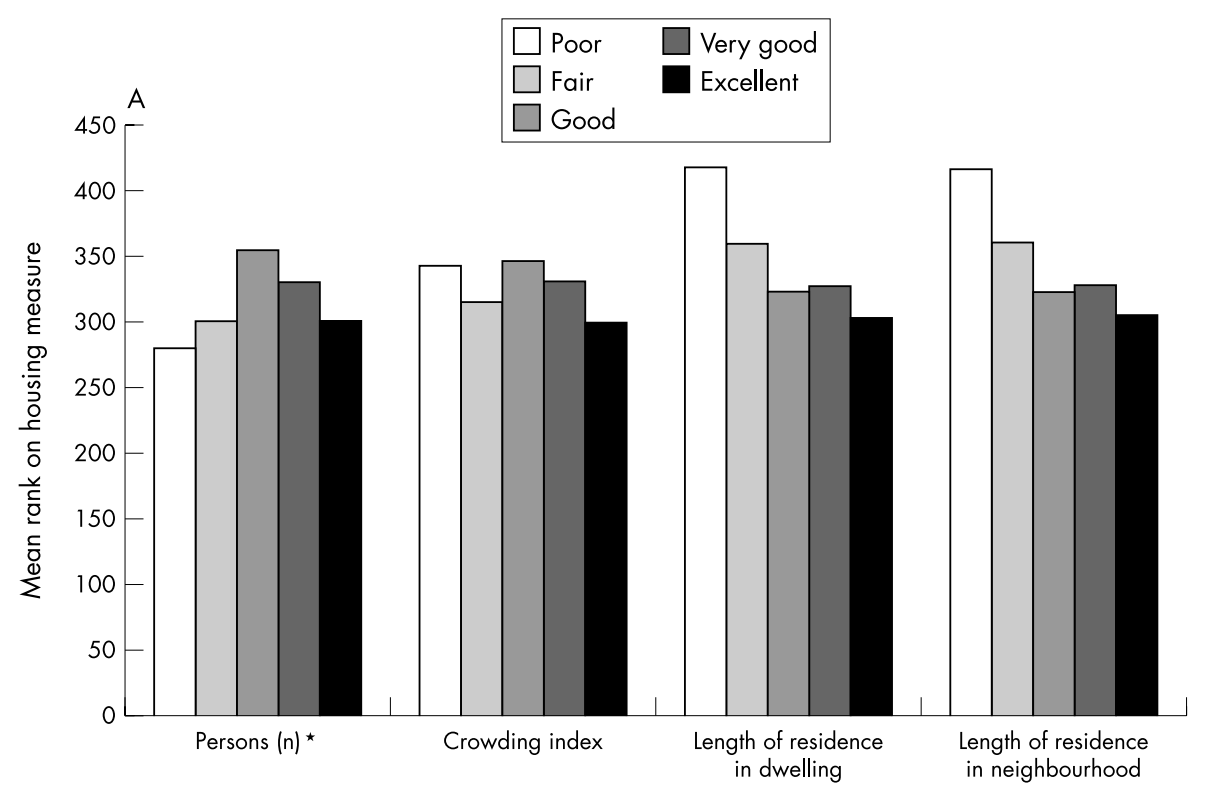

Figure 2 (A) Household attribututes and health status. (B) Household attributes and mental health. ${ }^{*} p<0.05,{ }^{* *} p<0.01,{ }^{* * *} p<0.001$.

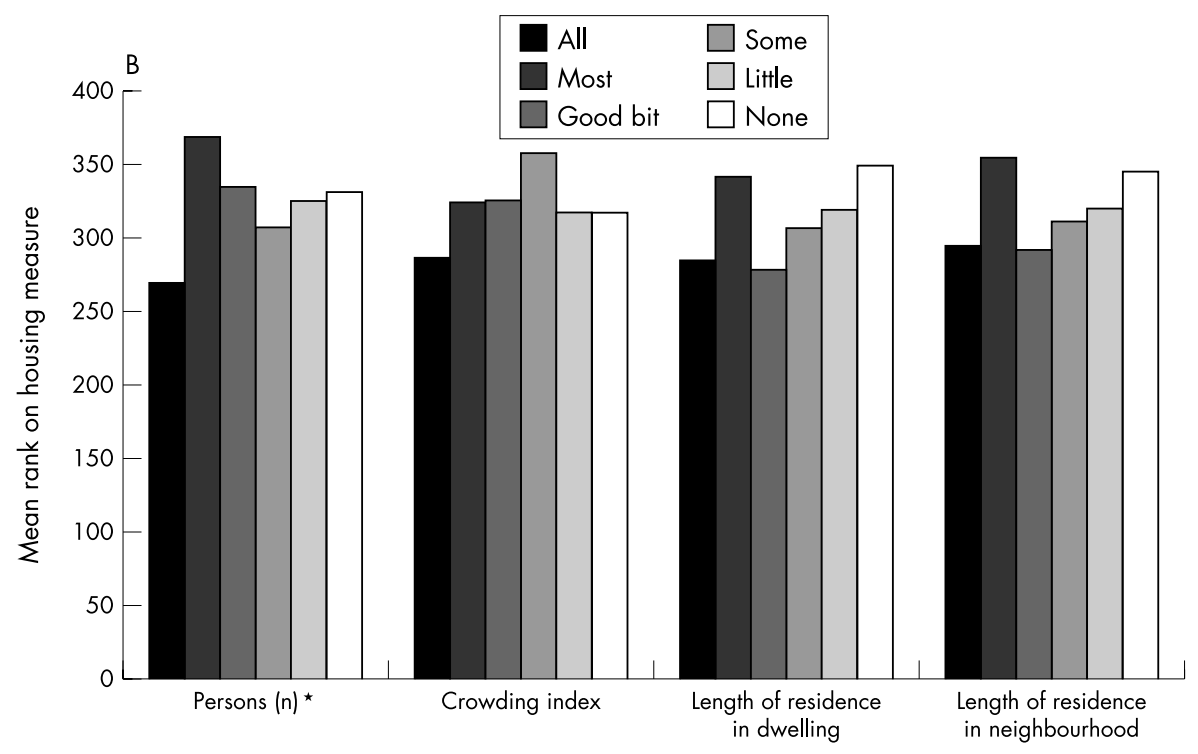

equity. A Mann-Whitney U test on housing tenure (owneroccupier versus tenant-not shown) against both health status measures showed that owner-occupiers were significantly more likely to report better mental health status $(p<0.01)$, but not self reported health.

In addition to the demonstrated association between housing costs and self reported health, figures $3 \mathrm{~A}$ and $3 \mathrm{~B}$ also show a graded relation between self reported strain of monthly housing costs and both self reported health status and the mental health measure. Respondents who reported greater strain in meeting their monthly housing costs were significantly more likely to report poorer general and mental health (with one inconsistency to the gradient in the case of mental health).

The other main source of housing demand investigated was domestic work (figs $4 \mathrm{~A}$ and $4 \mathrm{~B}$ ). There was no significant relation between self reported number of hours spent doing domestic work and either self rated health status or mental health, but there was a statistically significant general and mental health gradient in self rated strain of housework (with one inconsistency in the mental health gradient). Further analyses (not reported) revealed that there was a significant gender component to this relation, with women much more highly represented among those who reported their weekly housework to be a greater strain. The final variable tested for its relation to self rated health and mental health (shown in fig $4 \mathrm{~A}$ and $4 \mathrm{~B}$ ) was a general stress measure. It showed a statistically significant, monotonic health gradient for both general and mental health.

The importance of housing as a site for the exercise of control can be inferred from the fact that in Canadian culture, like most Western cultures, the home is one of the few places in an individual's everyday life where they are socially (and legally) sanctioned to have complete control. Coupled with the importance of control and decision latitude in the work and health literature, ${ }^{8}$ it follows that control in the home has the potential to be associated with health status. The results of analyses shown in figures $5 \mathrm{~A}$ and $5 \mathrm{~B}$ provide some support for this hypothesis. In general, respondents who reported that they couldn't stand to be at home "sometimes" or more were more likely to report poorer self rated health (nearly a monotonic gradient) and poorer mental health. Respondents who agreed more strongly that their home was a "good location to live their life" were significantly more likely to report better self reported health (in a nearly monotonic fashion), while the intergroup differences for mental health were not graded, despite being statistically significant. Finally, respondents who 


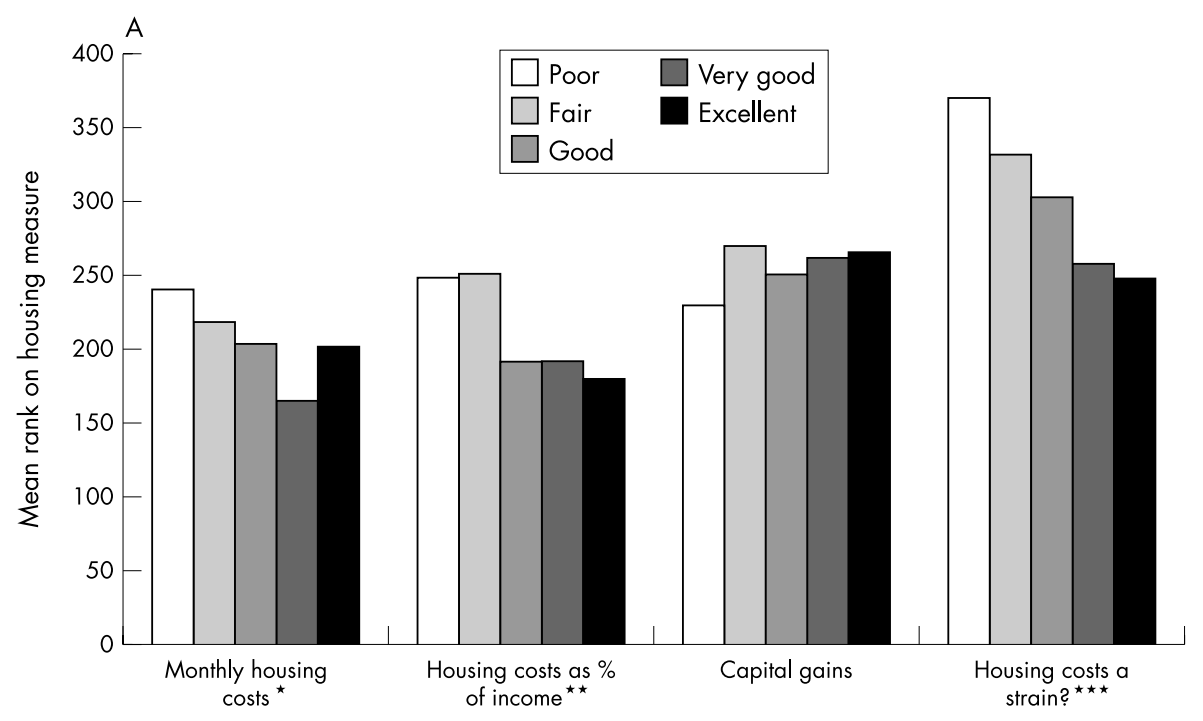

Figure 3 (A) Household finance and health status. (B) Household finance and mental health. ${ }^{*} p<0.05$ ${ }^{* *} p<0.01,{ }^{* * *} p<0.001$.

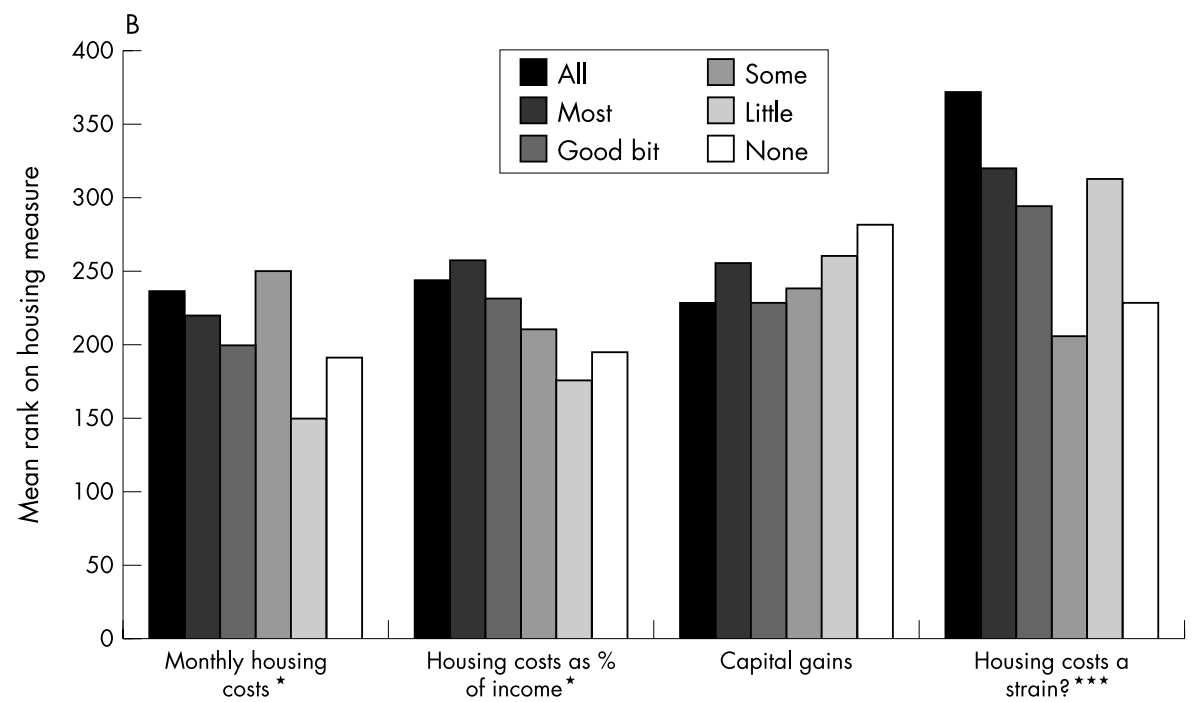

reported that they worried about being forced to move were significantly more likely to report poorer self reported health and mental health in a nearly monotonic gradient. These findings lend support to the hypothesis that control in the domestic environment could be an important factor in shaping socioeconomic differences in health.

The final dimension of housing investigated in this analysis, meaningfulness of housing, follows from Wilkinson's ${ }^{310}$ argument described in the introduction. The results here are mixed, with figures 6A and 6B showing no significant health differences for respondents who agreed more strongly that they felt they belonged in their neighbourhood. Pride in neighbourhood was associated with better general and mental health, in a predominantly graded fashion, consistent with Mitchell et al. ${ }^{14}$ Finally, respondents who agreed that their home was a good reflection of their identity were more likely to report better general and mental health. Similarly, respondents who agreed that they were proud of their dwelling (home) were significantly more likely to report good health, also in a (nearly) monotonic fashion.

\section{Logistic regression analysis}

The results of logistic regression analyses on the two outcome variables are shown in tables 2 and 3. In both instances the likelihood of the less favourable health outcome (fair/poor health or downhearted and blue a good bit of the time or more) is regressed on six thematic blocks of variables. Each block of variables was entered sequentially to build a cumulative model. Each block was entered using a backwards stepwise elimination procedure, except the sociodemographic characteristics block, which was forced into the model. Before calculating the regression equation for the first block, however, the single variable "age" was regressed on the likelihood of reporting fair or poor health, because of its a priori importance. The explanatory performance of subsequent iterations of the model was then compared with the performance of this base model containing only age as a covariate. Explanatory variables were tested for multi-collinearity using both parametric and non-parametric tests. Only length of residence in dwelling (LGTHDWEL) and length of residence in neighbourhood (LGTHHOOD) were strongly correlated $(r>0.8)$; no other variable pair showed a correlation greater than 0.5 and all but two pairs were below 0.4 . The removal of LGHTDWEL and then LGTHHOOD from the regression models did not substantially change the results reported here.

In the case of self rated health (table 2), when the first full block of variables was entered, education emerged as the only sociodemographic variable significantly related to the outcome, with each level of educational attainment being associated with roughly a fourfold reduction in the likelihood of reporting fair 


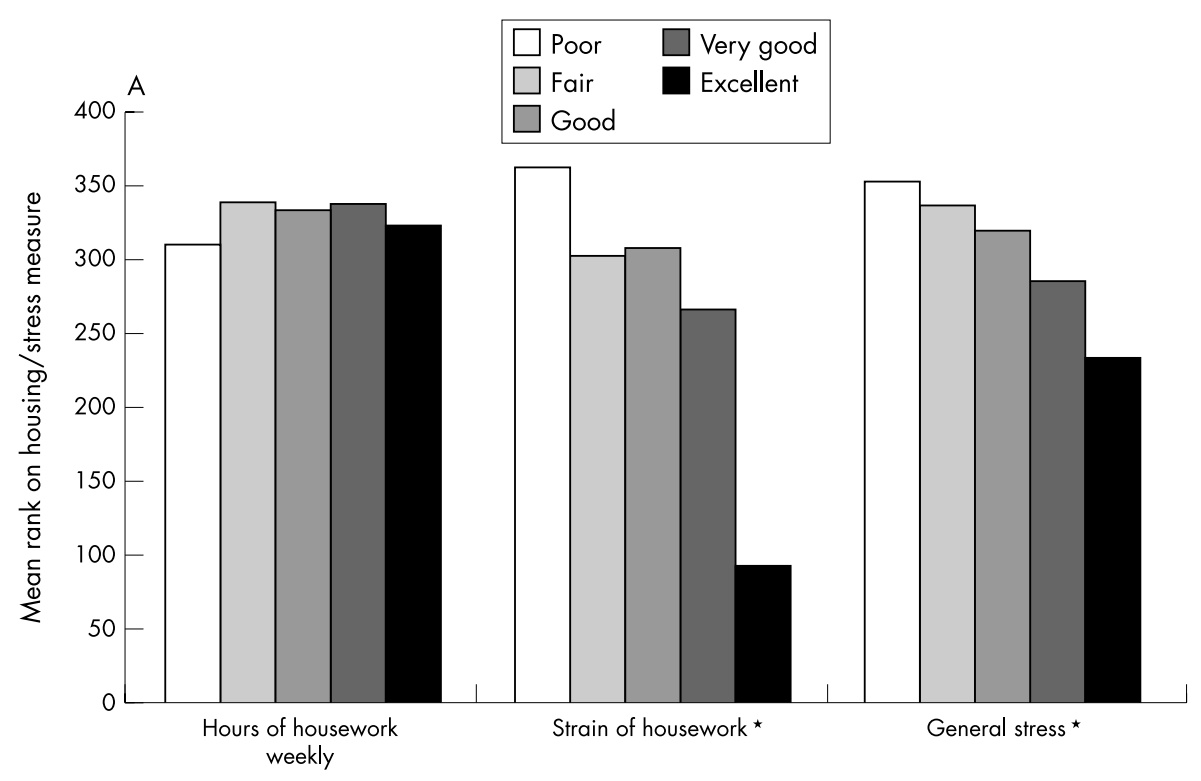

Figure 4 (A) Domestic work, stress, and health. (B) Domestic work, stress, and mental health. ${ }^{*} p<0.05$, ${ }^{* *} p<0.01,{ }^{* * *} p<0.001$.

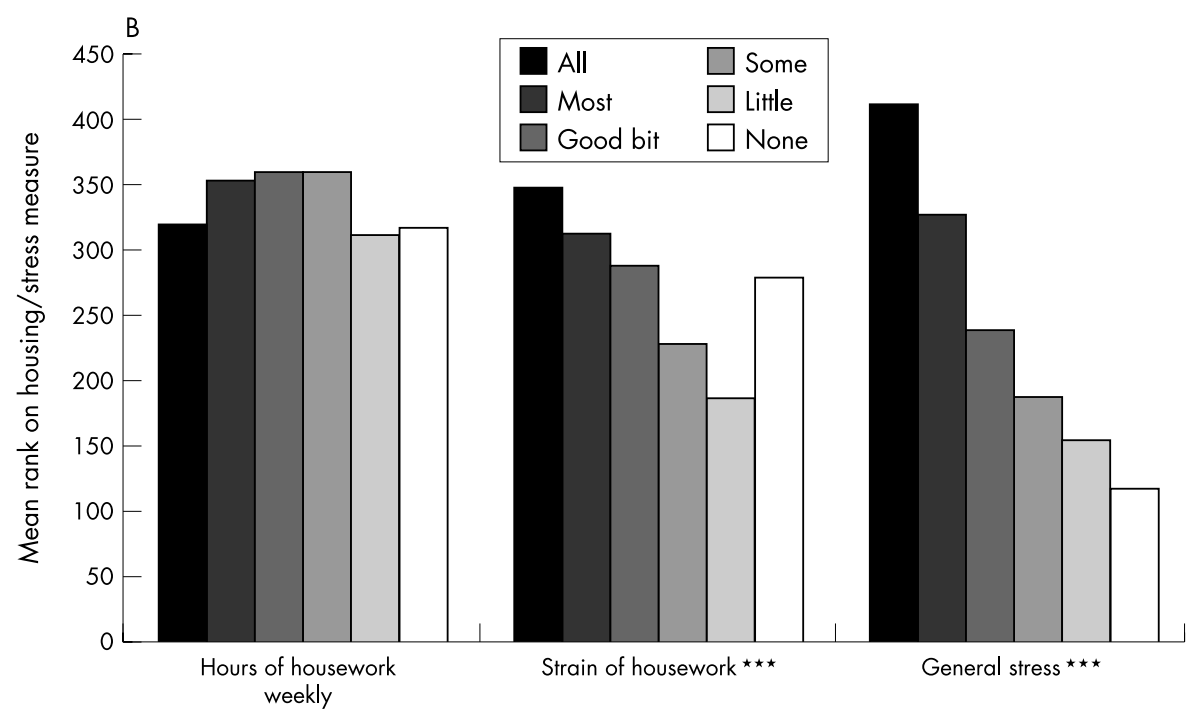

or poor health. The addition of the housing characteristics (tenure, crowding index, length of residence in dwelling, and length of residence in neighbourhood), added one variable to the model. Respondents living in rented dwellings were 2.11 times more likely to report fair/poor health than owneroccupiers $(\mathrm{p}<0.05)$, and education remained a significant contributor to the model with nearly the same odds ratio.

The addition of housing demand/control variables (hate to be at home sometimes; home a good location to live life; worry about a forced move; strain of housing costs; strain of housework) added three new variables, two of which were statistically significant in the model. Respondents were more likely to report fair/poor health if they: lived in a rented dwelling $(\mathrm{OR}=1.99, \mathrm{p}<0.05)$; ( strongly) agreed that they "hate to be at home sometimes" $(\mathrm{OR}=2.09, \mathrm{p}<0.05)$; and reported the strain of housework to be somewhat or quite a strain $(\mathrm{OR}=5.26, \mathrm{p}<0.001)$.

The addition of meaningful dimensions of housing (feel like you belong in your neighbourhood, proud of neighbourhood, home a good reflection of self, proud of dwelling) failed to make any contribution to the cumulative model. This occurred despite some evidence in the bivariate analysis of associations between these variables and self rated health. The addition of neighbourly social support variables (how friendly are your neighbours, how often to you talk with your neighbours, how often to you exchange help with your neighbours) also failed to add anything to the cumulative model, although this is consistent with the bivariate analyses above.

The final block of variables to be added were measures of general (non-residential, non-housing) social support, and overall stress (how often in the last two weeks have you felt "constantly under stress"). Not surprisingly, satisfaction with social life and general stress made strong and statistically significant contributions to the cumulative model. Respondents who were somewhat or very dissatisfied with their social life were 3.41 times more likely to report fair/poor health $(\mathrm{p}<0.001)$ and respondents who were constantly under stress a good bit of the time or more were 3.56 times more likely to report poorer health $(\mathrm{p}<0.05)$. "Hate to be at home" and strain of housework maintained their significance in the final cumulative model, but tenure lost statistical significance in the final model. The final cumulative model performed relatively well, showing a $\rho^{2}$ of 0.264 , which Wrigley ${ }^{23}$ describes as within the range of "very good fit".

The results for mental health (table 3 ) are similar to those of self rated health. The outcome measure in this case is the likelihood of a respondent reporting that they felt "downhearted and blue a good bit of the time" or more in the two 


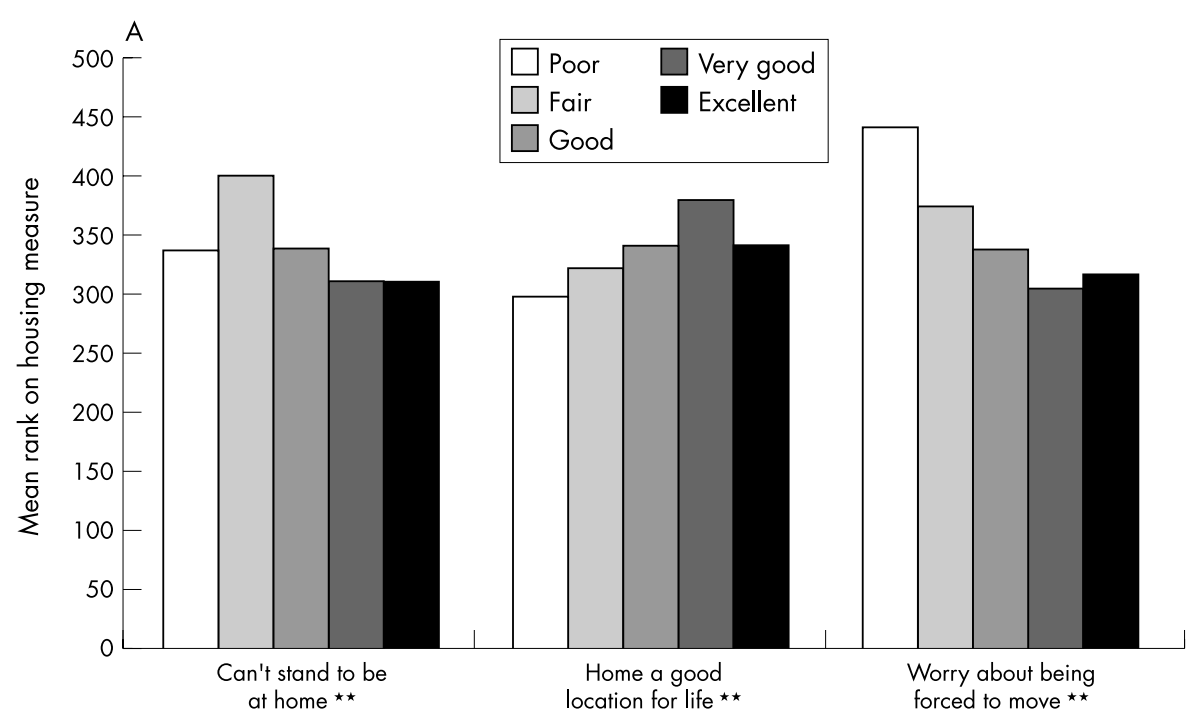

Figure 5 (A) Housing control and health. (B) Housing control and mental health. ${ }^{*} p<0.05,{ }^{* *} p<0.01$, ${ }^{* * *} p<0.001$.

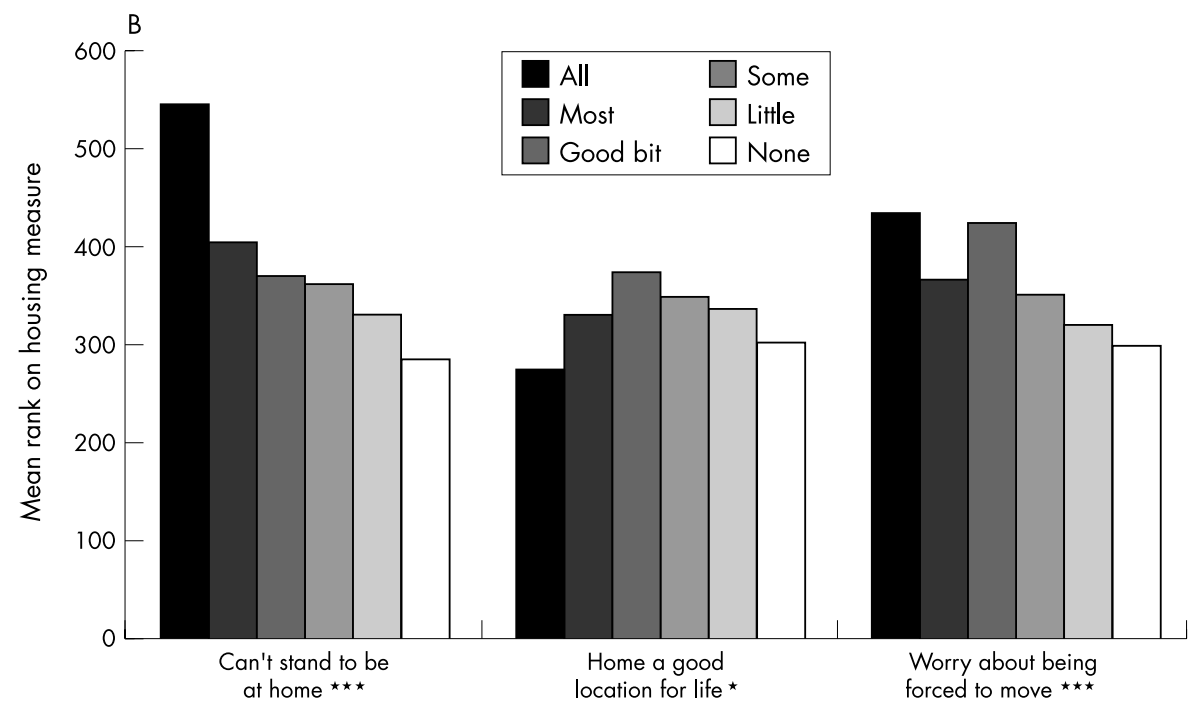

weeks before the interview. Table 3 shows that none of the sociodemographic variables were significantly associated with the outcome. After the addition of housing characteristics, tenure, and length of residence in neighbourhood remained in the model, with only the latter making a significant contribution $(\mathrm{OR}=1.03, \mathrm{p}<0.05)$. When housing demand/control variables were added, "hate to be at home sometimes" and "strain of housework" entered the model, both making a statistically significant contribution to the model. Housing tenure also emerged as a significant contributor. At this point in the modelling, respondents were more likely to report feeling downhearted and blue a good bit of the time or more if they: lived in a rented dwelling $(\mathrm{OR}=2.13, \mathrm{p}<0.05)$; lived longer in their neighbourhood ( $\mathrm{OR}=1.03, \mathrm{p}<0.05)$; (strongly) agreed that they hated to be at home sometimes $(\mathrm{OR}=2.42, \mathrm{p}<0.01)$; and reported their housework duties to be somewhat or quite a strain $(\mathrm{OR}=7.14, \mathrm{p}<0.001)$.

Similar to the case for self rated health, the addition of meaningful dimensions of home to the model made no impact. Neither pride in dwelling or neighbourhood, nor sense of belonging in neighbourhood or home as reflection of self remained in the model after being entered. Unlike the case for self rated health, however, one variable concerning neighbourly social support did remain in the model upon addition of that block of variables. Previous effects remained similar, and in addition, respondents who reported that their neighbours were (very) unfriendly were 2.6 times $(\mathrm{p}<0.05)$ more likely to have felt downhearted and blue a good bit of the time in the two weeks before the interview.

Upon addition of general social support and stress variables to the model, however, the three housing variables (tenure, hate to be at home, and neighbour friendliness) lost their significance. So in the final analysis, respondents were more likely to report feeling downhearted and blue a good bit of the time or more if they: lived longer in their neighbourhood $(\mathrm{OR}=1.05, \mathrm{p}<0.05)$; reported their housework duties to be somewhat or quite a strain $(\mathrm{OR}=5.55, \mathrm{p}<0.001)$; reported that they did not have somebody that could help them if they needed it $(\mathrm{OR}=9.28, \mathrm{p}<0.001)$; and reported that they were constantly under stress a good bit of the time or more in the two weeks before the interview $(\mathrm{OR}=5.26, \mathrm{p}<0.001)$.

\section{DISCUSSION}

The findings of this paper lend support to the hypothesis that features of the domestic environment, especially as they pertain to the exercise of control and the experience of demand, are significant predictors of self reported general and mental health status. Because of the cross sectional nature of the study, of course, it is impossible to be certain that the direction of causality in the relation between housing and 


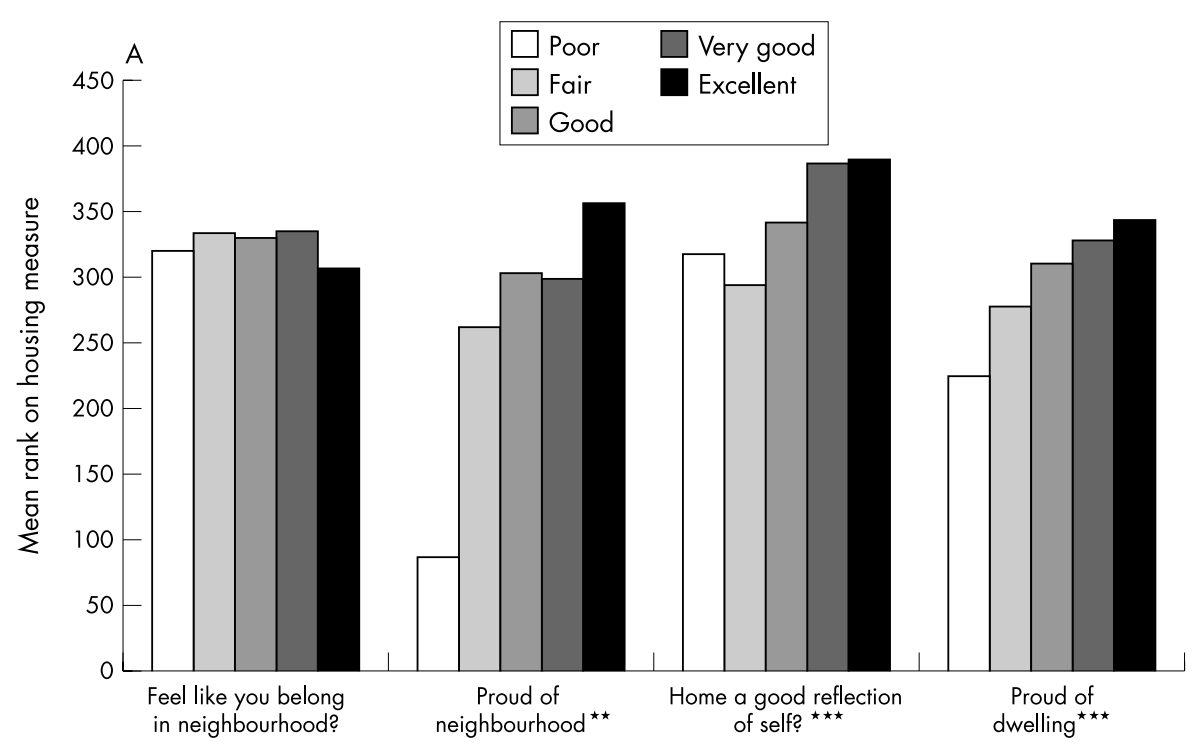

Figure 6 (A) Housing, identity, status, and health. (B) Housing, identity, status, and mental health. ${ }^{*} p<0.05,{ }^{* *} p<0.01,{ }^{* * *} p<0.001$.

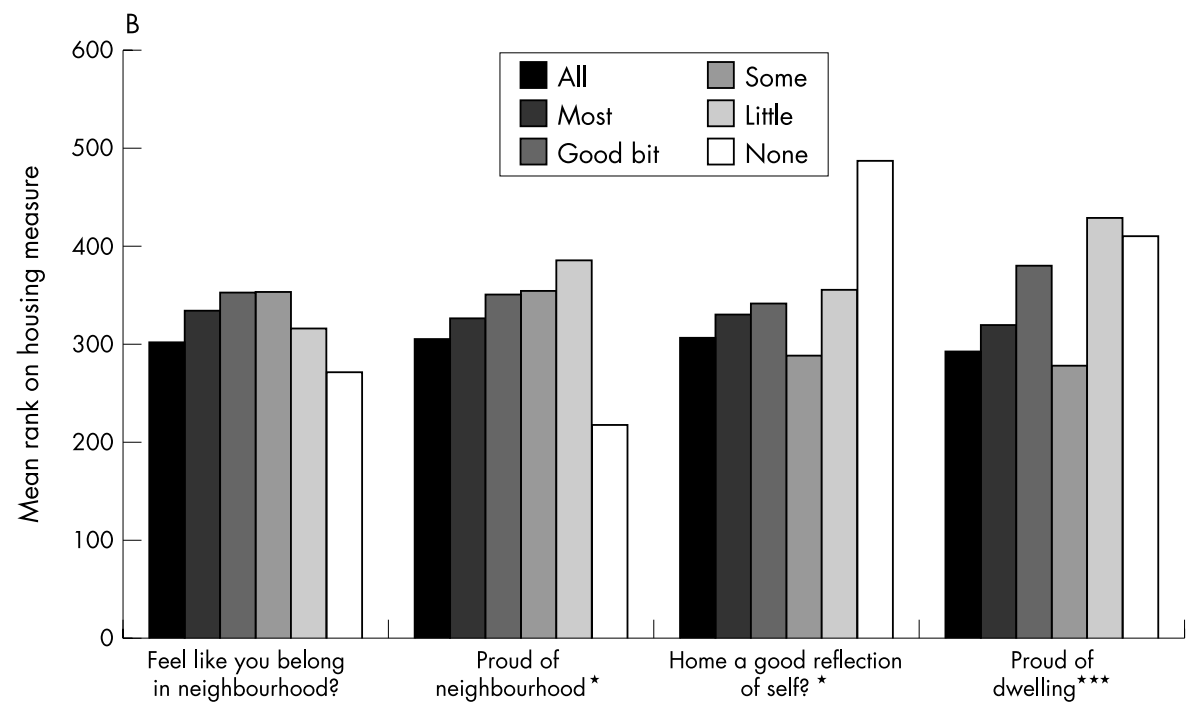

health is reversed. Previous longitudinal studies, however, have shown that the contribution of reverse causality to the socioeconomic gradient in health is small. ${ }^{24}{ }^{25}$ Bivariate analyses that tested for the existence of gradients in various housing demand and control factors, including housing tenure, showed relations with self rated general and mental health, consistent with previous research. ${ }^{26}{ }^{27}$ In multivariable analyses, demand and control factors were strong and significant contributors to logistic regression models for both health outcomes. The influence of housing demand and control variables superseded a well known correlate of health status, educational attainment, further attesting to their importance.

The other main hypothesis investigated in the foregoing, that meaningful dimensions of housing are associated with health status, found support in bivariate analyses without controls, but did not contribute to multivariable models. In the case of self reported general health status, strong and statistically significant evidence of graded relations between meaningful dimensions of housing was evident in bivariate analyses, and similar but weaker associations were observed between meaningful dimensions of housing and the mental health measure. In the multivariable analyses, meaningful dimensions of housing were not significant contributors to models for either health outcome.
Objective measures of housing, such as crowding and length of residence in dwelling or neighbourhood were not associated with either measure of health status in bivariate analyses. The failure of crowding to show an association with health contradicts a longstanding belief in health research. But in a post-epidemiological transition context, where the primary burden of illness is non-infectious conditions, this is a logical result.

This study has made a distinction between material and meaningful dimensions of housing, but in a number of instances, a given variable could be interpreted to be either meaningful or material. Housing tenure is an excellent example. On the one hand, the distinction between owner-occupiers and renters often represents a substantial cleavage in material wealth, property rights and control over everyday life circumstances. At the same time, however, many Western societies also ascribe a great deal of meaning, prestige, and status to home ownership, which may have a simultaneously positive effect..$^{26-28}$ It follows that the distinction between material and meaningful (roughly synonymous with "psychosocial") dimensions of socioeconomic status may be an artificial one and that the wider debate between material and psychosocial pathways ${ }^{29}{ }^{30}$ may falsely dichotomise concepts that are in fact fundamentally interdependent.

It is worth noting that the strength and significance of housing demand and control variables in the multivariable 
Table 2 Housing and self reported health logistic regression analysis

\begin{tabular}{|c|c|c|c|c|c|c|c|}
\hline & Age only & Sociodemographic & Housing & Demand/control & Meaning & Neighbours & Social support \\
\hline Age & 1.19 (1.02 to 1.39$)^{*}$ & $1.08(0.91$ to 1.29$)$ & 1.18 (0.98 to 1.42 ) & 1.2 (0.99 to 1.45 ) & $1.2(0.99$ to 1.45$)$ & 1.2 (0.99 to 1.45 ) & $1.16(0.95$ to 1.41$)$ \\
\hline Gender (female) & & 1.14 (0.64 to 2.01$)$ & 1.13 (0.63 to 1.99$)$ & $0.90(0.49$ to 1.66$)$ & $0.90(0.49$ to 1.66$)$ & $0.90(0.49$ to 1.66$)$ & $0.92(0.49$ to 1.72$)$ \\
\hline Education (high school) & & $0.26(0.11 \text { to } 0.60)^{* *}$ & $0.28(0.12 \text { to } 0.64)^{* *}$ & 0.43 (0.17 to 1.09$)$ & 0.43 (0.17 to 1.09$)$ & 0.43 (0.17 to 1.09$)$ & $0.46(0.17$ to 1.20$)$ \\
\hline Tenure (rent) & & & 2.11 (1.11 to 3.99$)^{*}$ & 1.99 (1.04 to 3.82$)^{*}$ & 1.99 (1.04 to 3.82 )* & 1.99 (1.04 to 3.82$)^{*}$ & 1.92 (0.99 to 3.71$)$ \\
\hline $\begin{array}{l}\text { Hate to be at home } \\
\text { (agree / strongly agree) }\end{array}$ & & & 1.18 (0.98 to 1.42$)$ & $2.09(1.11 \text { to } 3.93)^{*}$ & $2.09(1.11 \text { to } 3.93)^{*}$ & $2.09(1.11 \text { to } 3.93)^{*}$ & $2.29(1.20 \text { to } 4.39)^{*}$ \\
\hline $\begin{array}{l}\text { Worry about forced move } \\
\text { (agree / strongly agree) }\end{array}$ & & & & $1.94(0.93$ to 4.05$)$ & 1.94 (0.93 to 4.05$)$ & 1.94 (0.93 to 4.05$)$ & $1.88(0.88$ to 4.06$)$ \\
\hline $\begin{array}{l}\text { Strain of housework } \\
\text { (somewhat / great strain) }\end{array}$ & & & & $5.26(2.53 \text { to } 11.0)^{* * *}$ & $5.26(2.53 \text { to } 11.0)^{* * *}$ & $5.26(2.53 \text { to } 11.0)^{* * *}$ & $5.71(2.56 \text { to } 12.8)^{* * *}$ \\
\hline $\begin{array}{l}\text { Satisfaction with social life } \\
\text { (somewhat/very dissatisfied) }\end{array}$ & & & & & & & 3.41 (1.72 to 6.78$)^{* * *}$ \\
\hline $\begin{array}{l}\text { Constantly under stress } \\
\text { (good bit of time or more) }\end{array}$ & & & & & & & $3.56(1.25 \text { to } 10.2)^{*}$ \\
\hline-2 log likelihood & 416.541 & 354.846 & 349.354 & 322.294 & 322.294 & 322.294 & 306.596 \\
\hline$\rho^{2}$ & N/A & 0.148 & 0.161 & 0.226 & 0.226 & 0.226 & 0.264 \\
\hline
\end{tabular}

Table 3 Housing and mental health logistic regression analysis

\begin{tabular}{|c|c|c|c|c|c|c|c|}
\hline & Age only & Sociodemographic & Housing & Demand/control & Meaning & Neighbours & Social support \\
\hline Age & $0.87(0.71$ to 1.06$)$ & 0.86 (0.69 to 1.06$)$ & 0.79 (0.6 to 1.04 ) & 0.78 (0.59 to 1.04$)$ & 0.78 (0.59 to 1.04$)$ & 0.78 (0.59 to 1.04$)$ & 0.74 (0.54 to 1.007$)$ \\
\hline Gender (female) & & $1.02(0.55$ to 1.87$)$ & $0.97(0.52$ to 1.78$)$ & 0.75 (0.39 to 1.44$)$ & 0.75 (0.39 to 1.44$)$ & 0.74 (0.38 to 1.43 ) & 0.75 (0.36 to 1.53$)$ \\
\hline Education (high school) & & $0.52(0.17$ to 1.58$)$ & $0.64(0.21$ to 1.96$)$ & 1.47 (0.42 to 5.22$)$ & 1.47 (0.42 to 5.22$)$ & 1.59 (0.46 to 5.53$)$ & $2.18(0.47$ to 10.1$)$ \\
\hline Tenure (rent) & & & $1.99(0.96$ to 4.11$)$ & 2.13 (1.01 to 4.49$)^{*}$ & 2.13 (1.01 to 4.49$)^{*}$ & 2.12 (1.005 to 4.46$)^{*}$ & 1.86 (0.85 to 4.04$)$ \\
\hline $\begin{array}{l}\text { Length of residence in } \\
\text { neighbourhood (years) }\end{array}$ & & & 1.03 (1.002 to 1.07$)^{*}$ & 1.03 (1.001 to 1.07$)^{*}$ & 1.03 (1.001 to 1.07$)^{*}$ & 1.04 (1.002 to 1.07$)^{*}$ & $1.05(1.01 \text { to } 1.08)^{*}$ \\
\hline $\begin{array}{l}\text { Hate to be at home } \\
\text { (agree / strongly agree) }\end{array}$ & & & & $2.42(1.24 \text { to } 4.72)^{* *}$ & $2.42(1.24 \text { to } 4.72)^{* *}$ & 2.49 (1.27 to 4.86$)^{*}$ & 1.99 (0.95 to 4.15$)$ \\
\hline $\begin{array}{l}\text { Strain of housework } \\
\text { (somewhat / great strain) }\end{array}$ & & & & $7.3(3.29 \text { to } 16.1)^{* * *}$ & $7.3(3.29 \text { to } 16.1)^{* * *}$ & $7.14(3.21 \text { to } 15.9)^{* * *}$ & $5.59(2.31 \text { to } 13.5)^{* * *}$ \\
\hline $\begin{array}{l}\text { Neighbour friendliness } \\
\text { (unfriendly / very unfriendly) }\end{array}$ & & & & & & 2.6 (1.19 to 5.66 )* & 2.16 (0.92 to 5.12$)$ \\
\hline $\begin{array}{l}\text { Have someone to help when you } \\
\text { need it? (no) }\end{array}$ & & & & & & & $9.28(2.95 \text { to } 29.2)^{* * *}$ \\
\hline $\begin{array}{l}\text { Constantly under stress } \\
\text { (good bit of time or more) }\end{array}$ & & & & & & & $5.35(2.61 \text { to } 10.99)^{* * *}$ \\
\hline-2 log likelihood & $\begin{array}{l}359.249 \\
\text { N/A }\end{array}$ & 319.766 & $\begin{array}{l}313.584 \\
0127\end{array}$ & $\begin{array}{l}285.022 \\
0207\end{array}$ & 285.022 & 279.851 & 240.611 \\
\hline
\end{tabular}




\section{Key points}

- Housing is a significant engine of social inequality that has both material and psychosocial dimensions that may contribute to health differences.

- Self rated health was associated with housing tenure, housing demand, and housing control, after controlling for age, gender, and education.

- Mental health was associated with housing tenure, housing control, housing demand, and neighbour friendliness, after controlling for age, gender, and education

- Housing effects did not contribute to health as strongly as self assessed stress and social support.

- Housing factors may operate both directly and indirectly to modify the underlying factors shaping health status, like social support and stress.

analysis was attenuated by the addition of measures of social support and self reported stress. The result for respondents' experience of their home as a place of refuge was mixed. The variable created from a self rating on the statement "can't stand to be at home sometimes," maintained significance after the addition of social support and stress variables in the case of general self reported health, but lost significance in the case of the mental health measure.

The only housing related variables to occupy a strong and significant place in the multivariable analyses, after the addition of social support and stress variables, were "hate to be at home" (a measure of home as a refuge) and self rated demand of housework chores. As noted above, the pattern of reporting on strain of housework was strongly gendered, with women far more likely to rate their weekly housework as "a strain" or "quite a strain". This finding points to the need for future research to adopt a more explicitly gendered stance in the analysis of health effects of demand and control in domestic environments, but also with reference to work strain, as in the "double duty" hypothesis. ${ }^{31}{ }^{32}$

The dominance of social support and self reported stress in predicting general and mental health status is not too surprising, given the consistency of associations between social support and health and stress and health in the literature. That social support and stress "drown out" the effects of some housing demand and control variables, however, does not minimise the potential importance of the latter. It is plausible that interventions designed to increase control and reduce demand in the domestic environment could reduce overall levels of stress and enhance social support. Housing factors, in other words, may operate both directly and indirectly to modify the underlying factors shaping health status, like social support and stress.

The failure of meaningful dimensions of housing to reach statistical significance in multivariate analysis is somewhat paradoxical considering their statistically significant bivariate relation to general self rated health. Several possible explanations could be advanced. Firstly, it is possible that the meaningful dimensions of housing have been inadequately measured in this study. Secondly, it is possible that the meaningful dimensions of housing are captured by another variable, for example, housing tenure. Finally, it is possible that each individual dimension of the meaning of home (feeling of belonging in neighbourhood, home as a reflection of self, pride in dwelling, pride in neighbourhood) is not a universally relevant construct, but it may still be that meaningfulness of home in general is relevant. This is another area in need of further study, especially given claims about the importance of the meaning ascribed to material factors in the social production of health. ${ }^{10}$ Meaning, however, is created not just through its ascription to income, educational attainment, and place in the job hierarchy, it is also ascribed to the materiality of individuals' everyday life. Housing — central as it is as an expression of so many important social norms, economic security factors, and cultural symbols-is likely to be a pivotal feature of any understanding of the role of meaning, as well as materiality, in the social production of health.

\section{REFERENCES}

1 Engels F. The condition of the working class in England in 1844.1962 edn. London: 1844

2 Chadwick $\mathbf{E}$. The health of nations. A review of the works of Edwin Chadwick. London: Longmans, Green, 1887.

3 Wilkinson R. Unhealthy societies: The afflictions of inequality. London: Routledge, 1996.

4 Evans RG, Barer ML, Marmor TR, eds. Why are some people health and others not? The determinants of health of populations. New York: Aldine DeGruyter, 1994.

5 Tarlov AR. Social determinants of health: The sociobiological transition. In: Blane D, Brunner E, Wilkinson R, eds. Health and social organization. London: Routledge, 1996:71-93

6 Brunner $\mathbf{E}$. The social and biological basis of cardiovascular disease in office workers. In: Blane D, Brunner E, Wilkinson R, eds. Health and social organization. London: Routledge, 1996: 272-99.

7 Sapolsky R. One secret of health is more straightforward than you may think: money. Discovery 1998;April:46-52.

8 Karasek R, Theorell T. Healthy work: stress, productivity, and the reconstruction of working life. New York: Basic Books, 1990.

9 Dunn JR. Housing and health inequalities: review and prospects for research. Housing Studies 2000;15:341-66.

10 Wilkinson R. The epidemiological transition: from material scarcity to social disadvantage? Daedalus 1994;123:70

11 Despres C. The meaning of home: literature review and directions for future research and theoretical development. Journal of Architectural and Planning Research 1991;8:96-115.

12 Smith SG. The psychological construction of home life. Journal of Environmental Psychology 1994;14:125-136.

13 Burr K, Costanzo G, Hayes MV, et al. Mortality and health status in Vancouver: an analysis by neighbourhood areas. Victoria, BC: Ministry of Health and Ministry Responsible for Seniors, Division of Vital Statistics, 1995.

14 Mitchell R, Gleave S, Bartley M, et.al. Do attitude and area influence health? A multilevel approach to health inequalities. Health and Place 2000;6:67-79.

15 Ware J, Johnston S, Davies-Avery A, et al. Conceptualization and measurement of health for adults in the Health Insurance Study. Vol III. Mental health. Santa Monica: Rand Corporation, 1979.

16 van Doorslaer E, Wagstaff A, Bleichrodt $\mathrm{H}$, et al. Income-related inequalities in health: Some international comparisons. J Health Econ 1997; 16:93-112.

17 Hoeymans N, Feskens E, Kromhout D, et al. Ageing and the relationship between functional status and self-rated health in elderly men. Soc Sci Med 1997;45: 1527-36

18 Miilunpalo S, Vuori I, Oja P, et al. Self-rated health status as a health measure: the predictive value of self-reported health status on the use of physician services and on mortality in the working-age population. J Clin Epidemiol 1997;50;517-28

19 Gold M, Franks P, Erickson P. Assessing the health of a nation: the predictive validity of a preference-based measure and self-rated health. Med Care 1996;34:163-77

20 McDowell I, Newell C. Measuring health: a guide to rating scales and questionnaires. New York: Oxford University Press, 1996.

21 Berwick DM, Murphy JM, Goldman PA, et al. Performance of a five-item mental health screening test. Med Care 1991;29:169-76.

22 Weinstein MC, Berwick DM, Goldman PA, et al. A comparison of three psychiatric screening tests using receiver operating characteristics. Med Care 1989;27:593-607.

23 Wrigley N. Categorical data analysis for geographers and social scientists. New York: Longman Group, 1985.

24 Blane D, Davey Smith G, Bartley M. Social selection: what does it contribute to social class differences in health? Sociology of Health and Illness 1993; 15:1-15.

25 Lundberg 0 . Childhood living conditions, health status and social mobility: a contribution to the health selection debate. European Sociological Review 1991;7:149-62.

26 Macintyre S, Hiscock R, Kearns A, et al. Housing tenure and car access further exploration of the nature of their relations with health in a UK setting. J Epidemiol Community Health 2001;55:330-1.

27 Macintyre S, Ellaway A, Der G, et al. Do housing tenure and car access predict health because they are simply markers of income, or self esteem? A Scottish study. J Epidemiol Community Health 1998;52:657-64

28 Kearns A, Hiscock R, Ellaway A, et al. "'Beyond four walls" - the psycho-social benefits of home: evidence from West Central Scotland. Housing Studies 2000;15:387-410.

29 Lynch JW, Davey Smith G, Kaplan GA, et al. Income inequality and mortality: Importance to health of individual income, psychosocial environment, or material conditions. BM 2000;320:1200-4

30 Wilkinson RG. Two pathways, but how much do they differ? BM 1999:319:956-7.

31 Hall E. Double exposure: the combined impact of the home and work environments on psychosomatic strain in Swedish women and men. Int J Health Serv Res 1992;22:239-60.

32 Matthews S, Power C, Stansfeld SA. Psychological distress and work and home roles: a focus on socio-economic differences in distress. Psychol Med 2001;31:725-36. 